03

\title{
Электрические свойства пленок металлоорганических перовскитов
}

\author{
(C) А.М. Ершова ${ }^{1,2}$, М.К. Овезов ${ }^{1}$, И.П. Щербаков ${ }^{1}$, А.Н. Алешин ${ }^{1, \pi}$ \\ ${ }^{1}$ Физико-технический институт им. А.Ф. Иофрфе РАН, \\ Санкт-Петербург, Россия \\ ${ }^{2}$ Санкт-Петербургский государственный университет „ЛЭТИ“, \\ Санкт-Петербург, Россия \\ ฯ E-mail: aleshin@transport.ioffe.ru
}

(Поступила в Редакцию 30 сентября 2018 г.)

Исследованы электрические свойства пленок металлоорганических перовскитов $\mathrm{CH}_{3} \mathrm{NH}_{3} \mathrm{PbBr}_{3}$ и $\mathrm{CH}_{3} \mathrm{NH}_{3} \mathrm{PbI}_{3}$. Для образцов $\mathrm{CH}_{3} \mathrm{NH}_{3} \mathrm{PbBr}_{3}$ и $\mathrm{CH}_{3} \mathrm{NH}_{3} \mathrm{PbI}_{3}$ были измерены вольтамперные характеристики в диапазоне температур 300-80K, из которых были определены температурные зависимости удельного сопротивления, $\rho(T)$, имеющие характерные точки перегиба в области $160-240 \mathrm{~K}$. Были найдены энергии активации носителей заряда до и после точек перегиба. Предположено, что наблюдаемые особенности в температурных зависимостях удельного сопротивления (температура точек перегиба) коррелируют с температурами фазовых переходов из тетрагональной в орторомбическую фазы для двух исследованных металлоорганических перовскитов $\left(\mathrm{CH}_{3} \mathrm{NH}_{3} \mathrm{PbBr}_{3}\right.$ и $\left.\mathrm{CH}_{3} \mathrm{NH}_{3} \mathrm{~Pb}_{13}\right)$.

Авторы благодарны И.Н. Трапезниковой за помощь в измерении спектров поглощения.

DOI: $10.21883 /$ FTT.2019.02.47121.247

\section{1. Введение}

Материалы на основе металлоорганических перовскитов $\mathrm{CH}_{3} \mathrm{NH}_{3} M X_{3}(M=\mathrm{Pb}, \mathrm{Sn}, X=\mathrm{Cl}, \mathrm{Br}, \mathrm{I})$ привлекают большое внимание в связи с перспективами их использования в качестве активных слоев высокоэффективных солнечных элементов (СЭ) [1,2]. В 2018 г. к.П.д. СЭ на основе металлоорганических перовскитов достиг $\sim 23,3 \%$ [3]. Такая высокая эффективность перовскитных СЭ стала возможна благодаря эффективному поглощению света в видимом спектральном диапазоне, сбалансированным транспортным свойствам и большой диффузионной длине носителей заряда в таких материалах. Все эти свойства делают материалы на основе металлоорганических перовскитов перспективными для применения в качестве активных полупроводниковых слоев не только в СЭ, но и в полевых транзисторах, а также в светоизлучающих диодах нового поколения. Однако, несмотря на интенсивные исследования и большое количество публикаций на эту тему в мире, физические процессы, обусловливающие такую высокую эффективностью СЭ на основе металлоорганических перовскитов, по-прежнему остаются до конца не выясненными. В этой связи исследование механизма транспорта носителей заряда в таких материалах в широком диапазоне температур является важной и актуальной задачей. Обзор работ связанных с исследованием свойств, в том числе, механизма транспорта в различных металлоорганических перовскитах был сделан авторами работы [4]. В работе [5] были исследованы зависимости удельного сопротивления, $\rho(T)$, образцов различных металлорганических перовскитов, включая $\mathrm{CH}_{3} \mathrm{NH}_{3} \mathrm{PbI}_{3}$, при низких температурах. Полученные зависимости $\rho(T)$ имели активационный характер и были типичны для зависимо- стей $\rho(T)$ в нелегированных полупроводниках, однако демонстрировали значительный гистерезис при температурном циклировании - охлаждении и последующем нагреве. Авторами было сделано предположение, что наблюдаемый в металлорганических перовскитах гистерезис $\rho(T)$ возникает вследствие структурных фазовых переходов в таких материалах. Аналогичные результаты, но в более узком диапазоне температур (200-320 K) были получены в работе [6] для кристаллических и поликристаллических образцов $\mathrm{CH}_{3} \mathrm{NH}_{3} \mathrm{PbI}_{3}$. Ранее было показано, что в металлоорганических перовскитах на основе метиламмония $\left(\mathrm{MA}=\mathrm{CH}_{3} \mathrm{NH}_{3}^{+}\right.$) наблюдаются структурные фазовые переходы с изменением температуры из-за молекулярного движения катиона метиламмония относительно оси кристалла [2]. Вследствие этого $\mathrm{MAPb} X_{3}$ имеет температурно-зависимую кристаллическую структуру, в которой с понижением температуры были обнаружены фазовые переходы из кубической через тетрагональную в орторомбическую фазу. Фактически структурные фазовые переходы могут оказывать влияние как на BAX, так и на температурные зависимости $\rho(T)$ металлоорганических перовскитов при температурах, близких к температурам фазовых переходов по аналогии с температурными зависимостями полевой подвижности, полученными ранее для пленок $\mathrm{MAPb}_{3}$ в работе [7]. Недавно нами были исследованы электронные свойства полевых транзисторных структур на основе пленок $\mathrm{CH}_{3} \mathrm{NH}_{3} \mathrm{PbBr}_{3}$ [8] и температурные зависимости полевой подвижности в композитных пленках на основе проводящего полимера - полифлуорена и нанокристаллов перовскитов $\mathrm{CsPI}_{3}$, имеющие также активационный характер [9]. Однако детальных исследований температурных зависимостей удельного сопротивления пленок 
$\mathrm{MAPb} X_{3}$ вблизи температур структурных фазовых переходов до настоящего времени не проводилось.

Целью настоящей работы являлось исследование электрических свойств пленок металлоорганических перовскитов $\mathrm{CH}_{3} \mathrm{NH}_{3} \mathrm{PbBr}_{3}$ и $\mathrm{CH}_{3} \mathrm{NH}_{3} \mathrm{PbI}_{3}$ в диапазоне температур 300-80 K для определения особенностей транспорта носителей заряда в таких структурах.

Были измерены вольтамперные характеристики пленок $\mathrm{CH}_{3} \mathrm{NH}_{3} \mathrm{PbBr}_{3}$ и $\mathrm{CH}_{3} \mathrm{NH}_{3} \mathrm{PbI}_{3}$ и определены температурные зависимости удельного сопротивления, $\rho(T)$, имеющие характерные точки перегиба в области 160-240 К. Проведена оценка энергии активации носителей заряда до и после точек перегиба. Установлено, что наблюдаемые особенности в температурных зависимостях удельного сопротивления вблизи температуры точек перегиба коррелируют с температурами фазовых переходов из тетрагональной в орторомбическую фазы для двух исследованных металлоорганических перовскитов $\left(\mathrm{CH}_{3} \mathrm{NH}_{3} \mathrm{PbBr}_{3}\right.$ и $\left.\mathrm{CH}_{3} \mathrm{NH}_{3} \mathrm{PbI}_{3}\right)$.

\section{2. Объекты и методы исследования}

Для приготовления образцов были использованы порошки металлоорганических перовскитов $\mathrm{CH}_{3} \mathrm{NH}_{3} \mathrm{PbBr}_{3}$ с шириной запрещенной зоны $E_{g} \sim 2.3 \mathrm{eV}$ и $\mathrm{CH}_{3} \mathrm{NH}_{3} \mathrm{PbI}_{3}$ с $E_{g} \sim 1.55 \mathrm{eV}$, приобретенные у компании Xi'an Polymer Light Technology Corp. и примененные без дополнительной обработки. На рис. 1 показана структура металлоорганических перовскитов - $\mathrm{CH}_{3} \mathrm{NH}_{3} \mathrm{PbBr}_{3}$ и $\mathrm{CH}_{3} \mathrm{NH}_{3} \mathrm{PbI}_{3}$ (общепринятые обозначения - $\mathrm{MAPbBr}_{3}$ и $\left.\mathrm{MAPbI}_{3}\right)$ [2] использованных в нашей работе. Были изготовлены образцы пленок $\mathrm{CH}_{3} \mathrm{NH}_{3} \mathrm{PbBr}_{3}$ и $\mathrm{CH}_{3} \mathrm{NH}_{3} \mathrm{PbI}_{3}$ имеющие структуру $n-\mathrm{Si} / \mathrm{SiO}_{2} / \mathrm{Au} /$ $\mathrm{CH}_{3} \mathrm{NH}_{3} \mathrm{PbBr}_{3}\left(\mathrm{CH}_{3} \mathrm{NH}_{3} \mathrm{PbI}_{3}\right) / \mathrm{Au}$. В качестве подложки

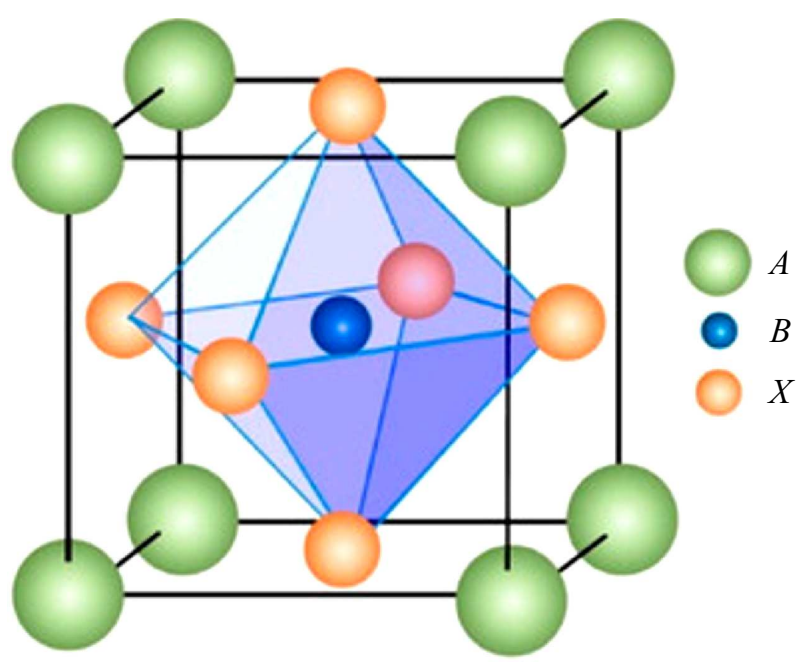

Рис. 1. Кристаллическая структура $A B X_{3}: A$ представляет собой органический катион, $B-$ тяжелый металл и $X-$ галоген. В нашем случае рассматривается соединение $\mathrm{CH}_{3} \mathrm{NH}_{3} \mathrm{~Pb} X_{3}$, где $X=\mathrm{Br}$ или I). использовались пластины сильно легированного $n^{+}$кремния с термически выращенным слоем $\mathrm{SiO}_{2}$ толщиной $200 \mathrm{~nm}$ в качестве диэлектрика с нанесенными методом термического испарения золотыми электродами. Расстояние между золотыми электродами составляло $\sim 15 \mu \mathrm{m}$, ширина электродов $\sim 1 \mathrm{~mm}$. Порошки $\mathrm{CH}_{3} \mathrm{NH}_{3} \mathrm{PbBr}_{3}$ и $\mathrm{CH}_{3} \mathrm{NH}_{3} \mathrm{PbI}_{3}$ растворялись в DMA $N, N$-Dimethylacetamide, затем растворы перемешивались ультразвуком в течение $10 \mathrm{~min}$ на ультразвуковой мешалке Bandelin Sonopuls HD $2070(f \sim 20 \mathrm{kHz})$. Полученные растворы наносились на подложки $\mathrm{Si} / \mathrm{SiO}_{2}$ с $\mathrm{Au}$ электродами методами полива или центрифугирования (при $3000 \mathrm{rpm})$. Нанесенные таким образом пленки высушивались при $100^{\circ} \mathrm{C}$ в атмосфере $\mathrm{N}_{2}$ в течение $15 \mathrm{~min}$. Толщина пленок полученных методом полива составляла $\sim 0.3-1.3 \mu \mathrm{m}$ согласно результатам атомносиловой микроскопии (АСM). Спектры поглощения пленок металлоорганических перовскитов нанесенных на кварцевые подложки (толщина $\sim 1 \mu \mathrm{m}$ ) исследовались с помощью спектрометра Cary-50 (Varian). Морфология пленок исследовалась с помощью АCM - P47-Solver NT-MDT. Спектры фотолюминесценции (ФЛ) пленок возбуждались с помощью ультрафиолетового светодиода LED UVTOP280TO39HS с длиной волны излучения $285 \mathrm{~nm}$. Излучение светодиода пропускалось через ультрафиолетовый фильтр UFS-8 и фокусировалось на поверхности образца при помощи кварцевой линзы с углом $\sim 10^{\circ}$ относительно нормали к поверхности образца в пятно диаметром $\sim 2 \mathrm{~mm}$. Спектры ФЛ регистрировались высокочувствительным волоконно-оптическим спектрометром со сверхмалым световым рассеянием „AVANTES“ - AvaSpec-ULSi2048L-USB2 OEM, paбoтающим в спектральном диапазоне $322-1100 \mathrm{~nm}$ со спектральным разрешением $4 \mathrm{~nm}$. Вольтамперные характеристики (BAX) пленок $\mathrm{CH}_{3} \mathrm{NH}_{3} \mathrm{PbBr}_{3}$ и $\mathrm{CH}_{3} \mathrm{NH}_{3} \mathrm{PbI}_{3}$, помещенных на держателе оптического проточного азотного криостата со стабилизацией температуры OPTCRYO198, измерялись в атмосфере азота в темноте при температуре $100-300 \mathrm{~K}$ с использованием автоматизированной измерительной установки на основе пикоамперметра Keithley 6487. Напряжение варьировалось с переменным шагом в пределах от -5 до $+5 \mathrm{~V}$. Электрические контакты к образцам изготовлялись с использованием серебряной проволоки, которая крепилась к металлическим электродам серебряной пастой.

\section{3. Результаты и обсуждение}

На рис. 2 приведены спектры поглощения $(1,2)$ и ФЛ $(3,4)$ пленок металлоорганических перовскитов $\mathrm{CH}_{3} \mathrm{NH}_{3} \mathrm{PbBr}_{3}$ и $\mathrm{CH}_{3} \mathrm{NH}_{3} \mathrm{PbI}_{3}$ соответственно измеренные при $300 \mathrm{~K}$. Как видно из рис. 2, спектр поглощения пленки $\mathrm{CH}_{3} \mathrm{NH}_{3} \mathrm{PbBr}_{3}$ имеет край поглощения в спектральном интервале $\sim 530-540 \mathrm{~nm}$, что хорошо согласуется с его шириной запрещенной зоны $E_{g} \sim 2.3 \mathrm{eV}$. Спектр ФЛ того же образца лежит 
в спектральной области $\sim 500-600 \mathrm{~nm}$. Для пленки $\mathrm{CH}_{3} \mathrm{NH}_{3} \mathrm{PbI}_{3}$ край поглощения варьируется в спектральном диапазоне $\sim 750-760 \mathrm{~nm}$, а его спектр ФЛ лежит

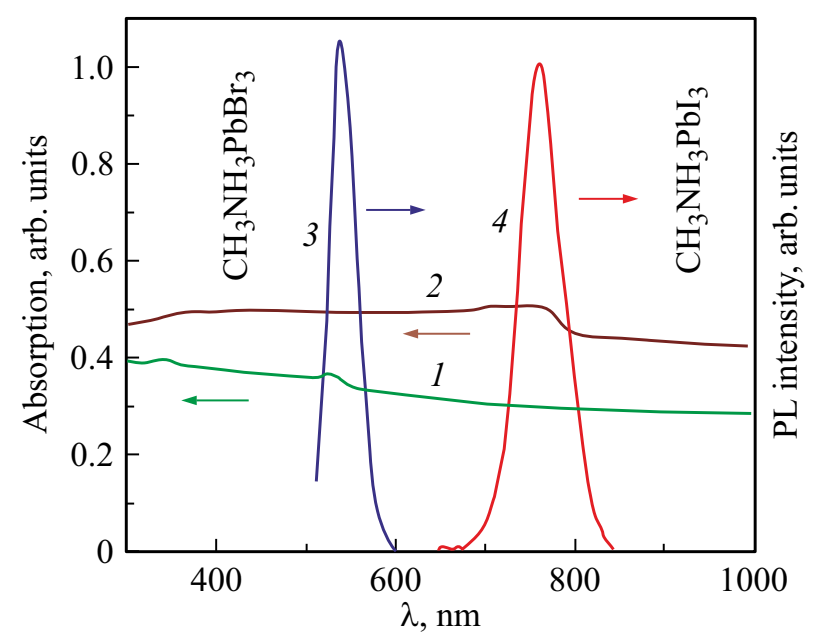

Рис. 2. Спектры поглощения $(1,2)$ и ФЛ $(3,4)$ для пленок $\mathrm{CH}_{3} \mathrm{NH}_{3} \mathrm{PbBr}_{3}$ и $\mathrm{CH}_{3} \mathrm{NH}_{3} \mathrm{PbI}_{3}$ соответственно.
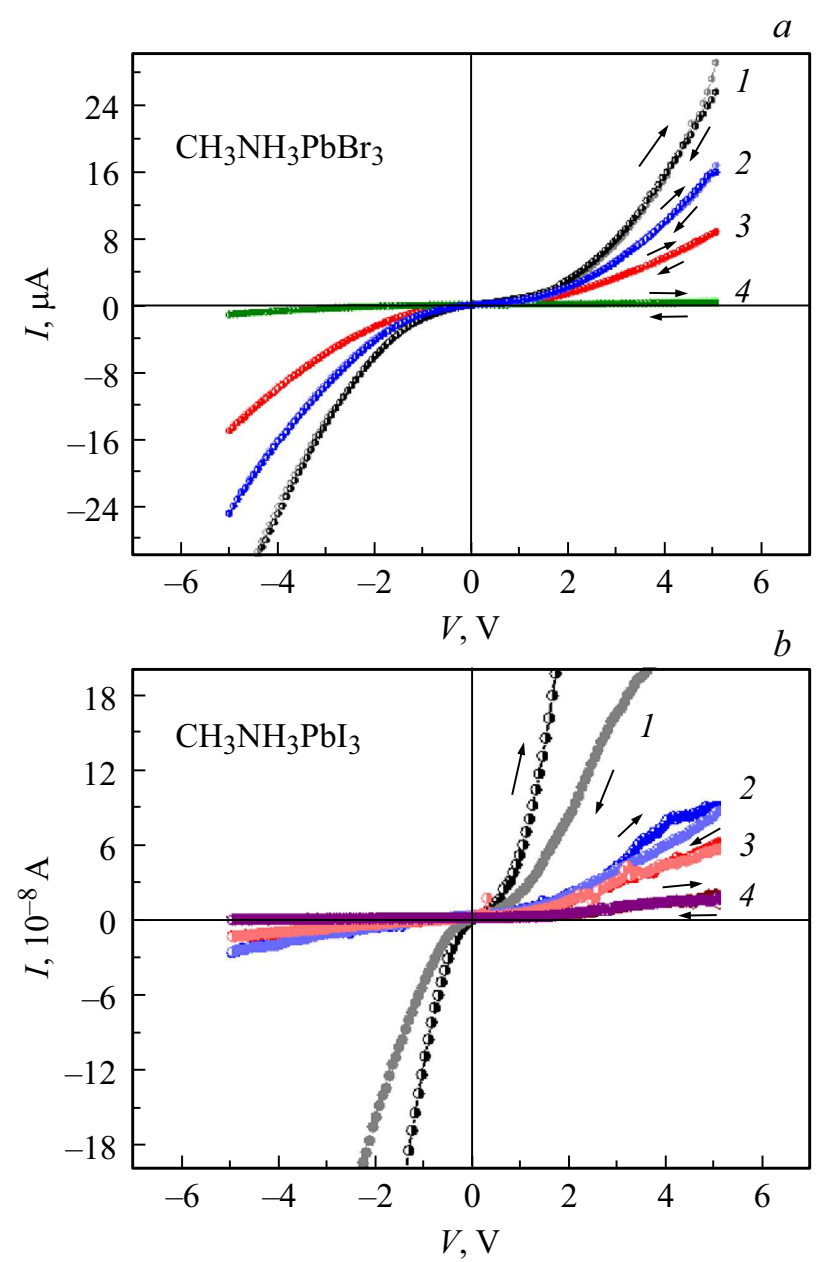

Рис. 3. Вольтамперные характеристики при прямом и обратном смещении для пленок $\mathrm{CH}_{3} \mathrm{NH}_{3} \mathrm{PbBr}_{3}$ (a) и $\mathrm{CH}_{3} \mathrm{NH}_{3} \mathrm{PbI}_{3}(b)$ при различных температурах, $\mathrm{K}: 1-280$; $2-240 ; 3-260 ; 4-180$.

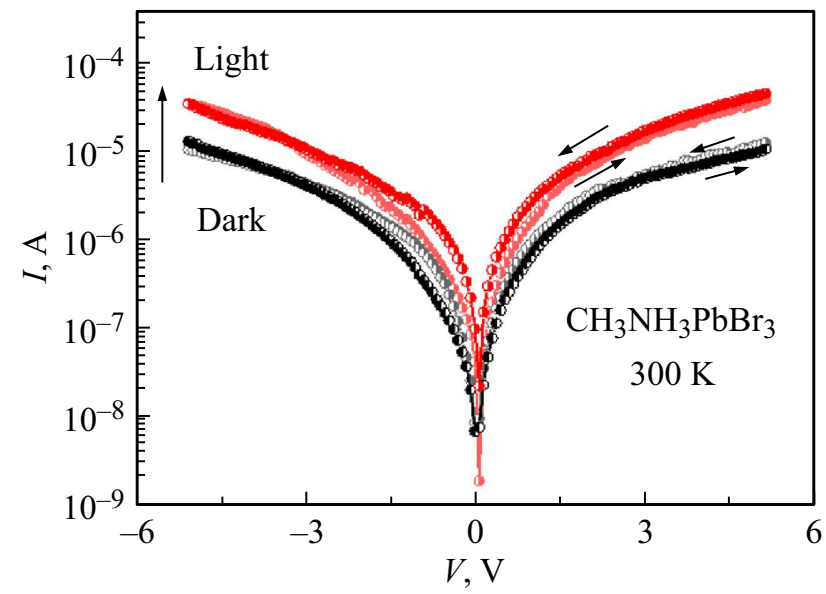

Рис. 4. Вольтамперная характеристика $\mathrm{CH}_{3} \mathrm{NH}_{3} \mathrm{PbBr}_{3}$ в темноте и при облучении белым светом.

в области $\sim 700-850 \mathrm{~nm}$ и имеет максимум, который хорошо согласуется с положением края поглощения с $T_{g} \sim 1.55 \mathrm{eV}$

Результаты анализа исследуемых пленок методом АCМ указывают на то, что толщина пленок, полученных методом полива, составила $\sim 0.3 \mu \mathrm{m}$ для $\mathrm{MAPbBr}_{3}$ и $\sim 1.3 \mu \mathrm{m}$ для $\mathrm{MAPbI}_{3}$. Исследованные пленки имеют неоднородную морфологию, которая характеризуется наличием микрокристаллитов с ярко выраженными границами, при этом средний диаметр микрокристаллитов для обоих образцов варьируется в пределах $\sim 400-800 \mathrm{~nm}$, а их высота - в пределах $\sim 30-80 \mathrm{~nm}$. Исследуемые пленки характеризуются значительной шероховатостью (Root Mean Square, Rq), которая составила для пленок $\mathrm{MAPbBr}_{3} \sim 32 \mathrm{~nm}$, для пленок $\mathrm{MAPbI}_{3} \sim 139 \mathrm{~nm}$.

На рис. 3, $a, b$ показаны типичные ВАХ при прямом и обратном смещении $\sim 1 \mathrm{~V}$ для пленок $\mathrm{CH}_{3} \mathrm{NH}_{3} \mathrm{PbBr}_{3}(a)$ и $\mathrm{CH}_{3} \mathrm{NH}_{3} \mathrm{PbI}_{3}$ (b) при различных температурах, K: $1-280 ; 2-240 ; 3-260 ; 4-180$. Как видно из рис. $3, a, b$, пленки $\mathrm{CH}_{3} \mathrm{NH}_{3} \mathrm{PbBr}_{3}$ имеют меньшее сопротивление по сравнению с $\mathrm{CH}_{3} \mathrm{NH}_{3} \mathrm{PbI}_{3}$ а также значительно меньший гистерезис ВАХ во всем диапазоне температур. На рис. 4 представлены типичные BAX исследованных образцов измеренные при $300 \mathrm{~K}$ в темноте и при освещении имитатором солнечного света с длиной волны в диапазоне 300-700 nm. Как следует из рис. 4, исследуемые пленки являются светочувствительными, так как наблюдается значительный рост тока при облучении образца белым светом: для пленок $\mathrm{CH}_{3} \mathrm{NH}_{3} \mathrm{PbBr}_{3}$ ток увеличился приблизительно в 5 раз, а для $\mathrm{CH}_{3} \mathrm{NH}_{3} \mathrm{PbI}_{3}$ - приблизительно в 3 раза. Зонные диаграммы для металлоорганических перовскитов $\mathrm{MAPbI}_{3}(a)$ и $\mathrm{MAPbBr}_{3}(b)$ показаны на рис. 5, $a, b$. Как следует из зонных диаграмм, преобладающим механизмом транспорта в таких структурах является инжекция дырок из золотых электродов в пленки металлоорганических перовскитов. 

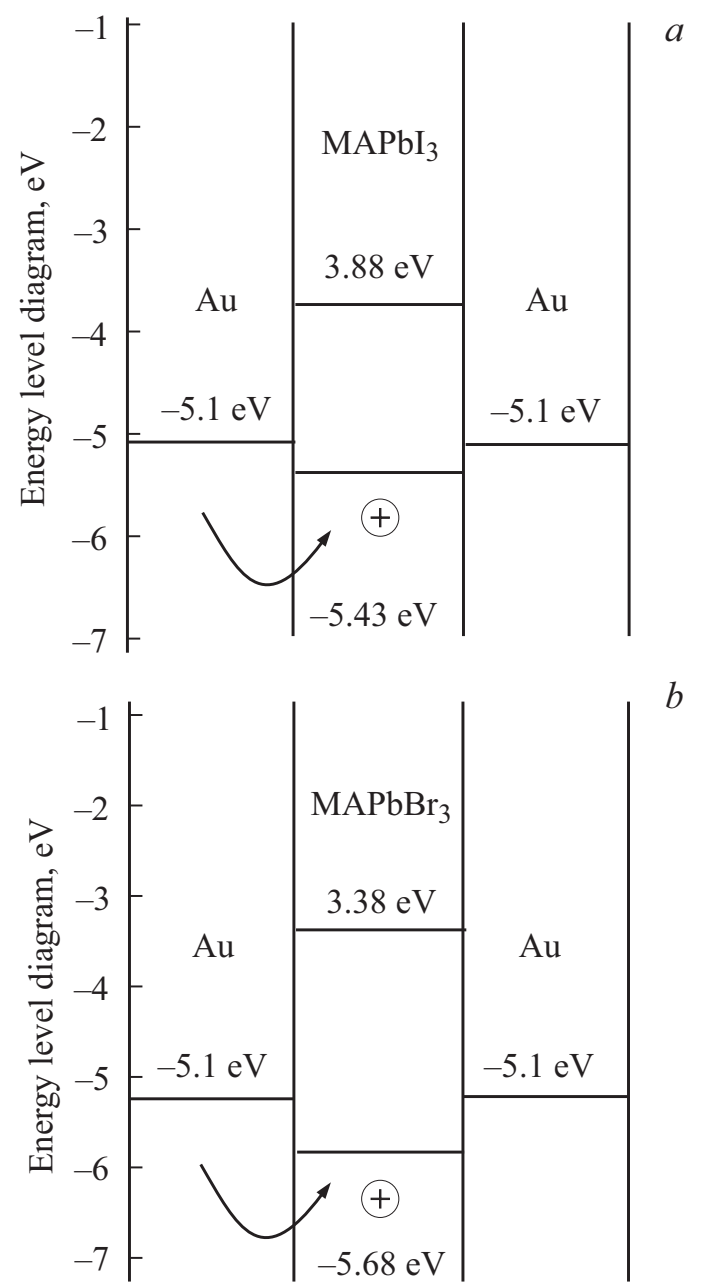

Рис. 5. Зонные диаграммы для a) $\mathrm{MAPbBr}_{3}$ и b) $\mathrm{MAPbI}_{3}$.

Для пленок $\mathrm{CH}_{3} \mathrm{NH}_{3} \mathrm{PbBr}_{3}$ и $\mathrm{CH}_{3} \mathrm{NH}_{3} \mathrm{PbI}_{3}$ по омическим участкам BAX, показанных на рис. $3, a, b$, были рассчитаны температурные зависимости удельного сопротивления, $\rho(T)$, которые изображены на рис. 6.' $a, b$. Как следует из рис. $6, a, b$, зависимости $\rho(T)$ для исследованных образцов имеют активационный характер и могут быть описаны выражением

$$
\rho(T)=\rho_{0} \exp \left(E_{\text {act }} / k_{\mathrm{B}} T\right)
$$

где $E_{\text {act }}-$ энергия активации, $T-$ температура, $k_{\mathrm{B}}-$ постоянная Больцмана. Энергии активации, $E_{\text {act }}$, вычислялись из температурных зависимостей удельного сопротивления по формуле

$$
E_{\text {act }}(\mathrm{meV})=(200 \Delta \lg \rho) /(\Delta 1000 / T),
$$

где $\rho$ - удельное сопротивление пленки; $T$ - температура. Полученные $E_{\text {act }}$ характеризуют энергию, необходимую для переноса электрона, в частности, из валентной зоны в зону проводимости, и являются характеристикой межмолекулярного взаимодействия. Таким образом, чем больше рассчитанная $E_{\text {act }}$, тем большая энергия требуется для активации носителей заряда (электронов и дырок) участвующих в процессах транспорта.

Из приведенных графиков видно, что как для пленок $\mathrm{CH}_{3} \mathrm{NH}_{3} \mathrm{PbBr}_{3}$, так и для пленок $\mathrm{CH}_{3} \mathrm{NH}_{3} \mathrm{PbI}_{3}$ зависимости $\rho(T)$ носят активационный характер во всем интервале температур. При этом для обоих образцов при определенной температуре, $T_{t}$, наблюдается изменение в характере зависимостей $\rho(T)$, а именно, переход от большей (при $T=300-160 \mathrm{~K}$ ) к меньшей (при $160-100 \mathrm{~K})$ энергии активации. Интервал температур такого перехода варьируется в интервале от 160 до $240 \mathrm{~K}$. Например, для образца $\mathrm{CH}_{3} \mathrm{NH}_{3} \mathrm{PbBr}_{3} T_{t}$ составила $160 \mathrm{~K}$. При этом величины $E_{\text {act }}$ для $\mathrm{CH}_{3} \mathrm{NH}_{3} \mathrm{PbBr}_{3}$ и $\mathrm{CH}_{3} \mathrm{NH}_{3} \mathrm{PbI}_{3}$ отличается примерно в два раза энергия активации пленок $\mathrm{CH}_{3} \mathrm{NH}_{3} \mathrm{PbBr}_{3}$ меньше, чем у $\mathrm{CH}_{3} \mathrm{NH}_{3} \mathrm{PbI}_{3}$. Согласно нашим оценкам, для пленок $\mathrm{CH}_{3} \mathrm{NH}_{3} \mathrm{PbBr}_{3}$ энергия активации в тетрагональной структуре составила $\Delta E_{a} \sim 121 \mathrm{meV}$, а в орторомбической $-\Delta E_{a} \sim 54 \mathrm{meV}$, тогда как для пленок $\mathrm{CH}_{3} \mathrm{NH}_{3} \mathrm{PbI}_{3}$ было получено $\Delta E_{a} \sim 430 \mathrm{meV}$ в тетрагональной и $\Delta E_{a} \sim 189 \mathrm{meV}$ в орторомбической структу-
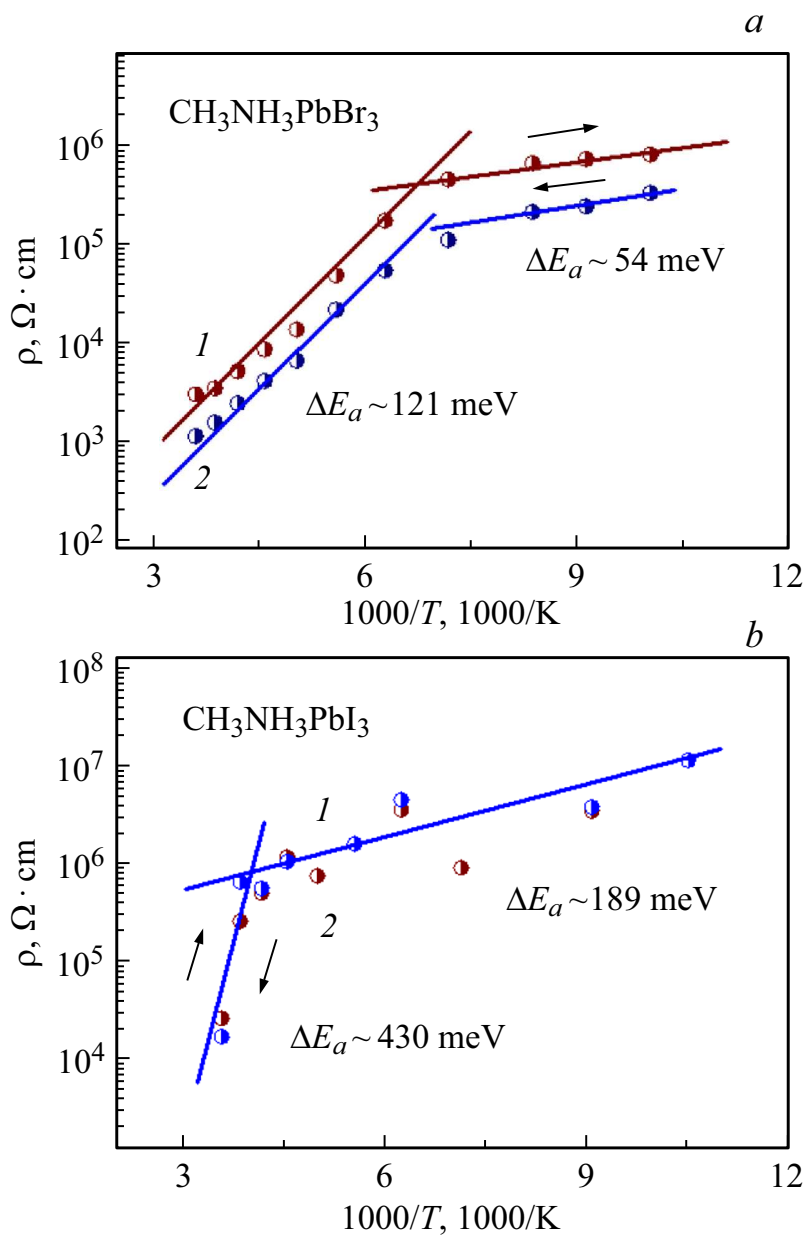

Рис. 6. Температурная зависимость удельного сопротивления для пленки $\mathrm{CH}_{3} \mathrm{NH}_{3} \mathrm{PbBr}_{3}$ (a) и $\mathrm{CH}_{3} \mathrm{NH}_{3} \mathrm{PbI}_{3}$ (b) при положительном (1) и отрицательном (2) напряжении $( \pm 1 \mathrm{~V})$ на образцах. 
pax. Энергия активации пленок $\mathrm{CH}_{3} \mathrm{NH}_{3} \mathrm{PbBr}_{3}$ меньше, чем у $\mathrm{CH}_{3} \mathrm{NH}_{3} \mathrm{PbI}_{3}$, что, возможно, связано с более высокой концентрацией электрически активных примесей в этом материале и с меньшей способностью к окислению пленок $\mathrm{CH}_{3} \mathrm{NH}_{3} \mathrm{PbBr}_{3}$ по сравнению с $\mathrm{CH}_{3} \mathrm{NH}_{3} \mathrm{PbI}_{3}$. Наблюдаемые в пленках $\mathrm{CH}_{3} \mathrm{NH}_{3} \mathrm{PbBr}_{3}$ и $\mathrm{CH}_{3} \mathrm{NH}_{3} \mathrm{PbI}_{3}$ зависимости $\rho(T)$, как правило, объясняются термической активацией носителей с примесных уровней (при более высоких температурах) и прыжковой проводимостью внутри примесных уровней (при низких температурах) [7], а также вкладом поляронного транспорта в перенос носителей заряда в металлоорганических перовскитах [10]. Однако, как было отмечено ранее, $\mathrm{MAPb}_{3}$ имеет температурно-зависимую кристаллическую структуру, в которой с понижением температуры наблюдаются кубические $\rightarrow$ тетрагональные $\rightarrow$ орторомбические фазовые переходы [2]. Полученные в нашей работе характерные температуры, $T_{t}$, в определенной степени коррелируют с температурой фазового структурного перехода из тетрагональной в орторомбическую фазу при низких температурах $(150-162 \mathrm{~K})$ в исследованных пленках металлоорганических перовскитов. Это позволяет предположить, что наблюдаемый нами при понижении температуры переход в зависимости $\rho(T)$ при определенной $T_{t}$ от большей к меньшей энергии активации, также как и гистерезис BAX, может быть связан со структурными фазовыми переходами в исследуемых пленках перовскитов $\mathrm{MAPb} X_{3}$. При этом изменение параметров решетки при низких температурах приводит к формированию микротрещин и изменению морфологии [5], что отражается и на транспортных свойствах.

\section{4. Заключение}

Получены образцы и исследованы электрические свойства пленок на основе растворимых металлоорганических перовскитов $\mathrm{CH}_{3} \mathrm{NH}_{3} \mathrm{PbBr}_{3}$ и $\mathrm{CH}_{3} \mathrm{NH}_{3} \mathrm{PbI}_{3}$. Исследования ВАХ в зависимости от температуры показали, что в интервале $160-240 \mathrm{~K}$ с понижением температуры, при характерных температурах $T_{t}$, наблюдается значительное уменьшение энергии активации и рост удельного сопротивления пленок. Установлено, что в пленках $\mathrm{CH}_{3} \mathrm{NH}_{3} \mathrm{PbBr}_{3}$ характерные энергии активации ниже, чем в пленках $\mathrm{CH}_{3} \mathrm{NH}_{3} \mathrm{PbI}_{3}$. Предположено, что температуры $T_{t}$ коррелируют с температурой фазовых структурных переходов из тетрагональной в орторомбическую фазу при низких температурах $(150-162 \mathrm{~K})$ в исследованных пленках перовскитов.

\section{Список литературы}

[1] L.K. Ono, Y. Qi. J. Phys. D 51, 093001 (2018).

[2] H.S. Jung, N.-G. Park. Small 11, 10 (2015).

[3] National Renewable Energy Laboratory, Best Research Cell Efficiencies; https://www.nrel.gov/pv/assets/images/efficiencychart.png; accessed: August 2018.
[4] A.K. Chilvery, A.K. Batra, B. Yang, K. Xiao, P. Guggilla, M.D. Aggarwal, R. Surabhi, R.B. Lal, J.R. Currie, B.G. Penn. J. Photon. Energy 5, 057402 (2015).

[5] C.C. Stoumpos, C.D. Malliakas, M.G. Kanatzidis. Inorg. Chem. 52, 9019 (2013).

[6] A. Pisoni, J. Jaćimović, O.S. Barišić, M. Spina, R. Gaál, L. Forró, E. Horváth. J. Phys. Chem. Lett. 5, 2488 (2014).

[7] S.P. Senanayak, B. Yang, T.H. Thomas, N. Giesbrecht, W. Huang, E. Gann, B. Nair, K. Goedel, S. Guha, X. Moya, C.R. McNeill, P. Docampo, A. Sadhanala, R.H. Friend, H. Sirringhaus. Sci. Adv. 3, e1601935 (2017).

[8] А.Н. Алешин, И.П. Щербаков, И.Н. Трапезникова, В.Н. Петров. ФТТ 58, 1818 (2016).

[9] A.N. Aleshin, I.P. Shcherbakov, E.V. Gushchina, L.B. Matyushkin, V.A. Moshnikov. Organ. Electron. 50, 213 (2017).

[10] M. Zhang, X. Zhang, L.-Y. Huang, H.-Q. Lin, G. Lu. Phys. Rev. B 96, 195203 (2017).

Редактор Е.Ю. Флегонтова 